ORIGINAL ARTICLE

\title{
Selection of promising fungal biological control agent of the western flower thrips Frankliniella occidentalis (Pergande)
}

\author{
S. Niassy ${ }^{1}$, N.K. Maniania ${ }^{1}$, S. Subramanian ${ }^{1}$, L.M. Gitonga ${ }^{2}$, D.M. Mburu ${ }^{1}$, D. Masiga ${ }^{1}$ and S. Ekesi ${ }^{1}$ \\ 1 International Centre of Insect Physiology and Ecology (icipe), Nairobi, Kenya \\ 2 Jomo Kenyatta University of Agriculture and Technology (JKUAT), Nairobi, Kenya
}

\section{Keywords}

Beauveria bassiana, biological control, genotyping, Metarhizium anisopliae, thrips.

\section{Correspondence}

Nguya K. Maniania, International Centre of Insect Physiology and Ecology (icipe), PO Box 30772-00100, Nairobi, Kenya.

E-mail: nmaniania@icipe.org

2011/1995: received 23 November 2011, revised 3 February 2012 and accepted 3 February 2012

doi:10.1111/j.1472-765X.2012.03241.x

\begin{abstract}
Aims: Larval stages of Frankliniella occidentalis are known to be refractory to fungal infection compared with the adult stage. The objective of this study was to identify promising fungal isolate(s) for the control of larval stages of F. occidentalis.

Methods and Results: Ten isolates of Metarhizium anisopliae and eight of Beauveria bassiana were screened for virulence against second-instar larvae of F. occidentalis. Conidial production and genetic polymorphism were also investigated. Metarhizium anisopliae isolates ICIPE 7, ICIPE 20, ICIPE 69 and ICIPE 665 had the shortest $\mathrm{LT}_{50}$ values of 8.0-8.9 days. ICIPE 69, ICIPE 7 and ICIPE 20 had the lowest $\mathrm{LC}_{50}$ values of $1.1 \times 10^{7}, 2.0 \times 10^{7}$ and $3.0 \times 10^{7}$ conidia $\mathrm{ml}^{-1}$, respectively. Metarhizium anisopliae isolate ICIPE 69 produced significantly more conidia than M. anisopliae isolates ICIPE 7 and ICIPE 20. Internally transcribed spacers sequences alignment showed differences in nucleotides composition, which can partly explain differences in virulence.

Conclusion: These results coupled with the previous ones on virulence and field efficacy against other species of thrips make M. anisopliae isolate ICIPE 69 a good candidate.

Significance and Impact of the Study: Metarhizium anisopliae isolate ICIPE 69 can be suggested for development as fungus-based biopesticide for thrips management.
\end{abstract}

\section{Introduction}

The western flower thrips (WFT), Frankliniella occidentalis Pergande (Thysanoptera: Thripidae), is a serious quarantine pest of horticultural crops worldwide (Lewis 1997; EPPO 2002). In addition to crop damages such as abscission of buds, abortion of flowers and malformation of pods, WFT are efficient vectors of tospoviruses (Lewis 1997). Synthetic chemical pesticides are widely used for control of thrips, despite their toxicity and hazardous effects to humans and the environment (Kirk and Terry 2003; Nderitu et al. 2008). In addition, the WFT have developed resistance to major groups of synthetic chemicals (Jensen 2004; Broughton and Herron 2009). There is therefore the prevailing need to develop ecologically sound and sustainable alternative for management of thrips. Entomopathogenic fungi are among the control strategies being developed (Ekesi and Maniania 2000a; Ekesi et al. 2007). For instance, Maniania et al. (2002) reported that application of Metarhizium anisopliae (Metschnikoff) Sorokin (Hypocreales: Clavicipitaceae) significantly reduced WFT in chrysanthemum crop, but the control of larval populations was much lower than for adults. Similar observations were made in laboratory bioassays by Vestergaard et al. (1995) and Ugine et al. (2005) with M. anisopliae and Beauveria bassiana (Balsmo) Vuillemin. The objective of this study was therefore to screen different fungal isolates of $M$. anisopliae and B. bassiana for selection of virulent isolate(s) against second-instar larval stage of WFT. We also considered other 
parameters such as conidial production and evolutionary phylogenetic variability among the fungal isolates using molecular tools.

\section{Materials and methods}

\section{Insect colony}

Insects were obtained from the Mass Rearing Unit at the International Centre of Insect Physiology and Ecology (icipe). They were reared on French bean pods Phaseolus vulgaris (L.) var. Samantha at $25 \pm 2{ }^{\circ} \mathrm{C}, 60-80 \%$, r.h. with a $12 \mathrm{~L}: 12 \mathrm{D}$ photoperiod. Second-instar larval stage was used in the experiments.

\section{Fungus}

Fungal isolates were obtained from the icipe's Arthropod Germplasm Centre (Table 1). They were cultured on Sabouraud Dextrose Agar (SDA) in 9-cm Petri dishes and incubated at $25 \pm 2^{\circ} \mathrm{C}$ in complete darkness. Conidia were harvested by scrapping the surface using a spatula. Inocula were suspended in $10 \mathrm{ml}$ sterile distilled water containing $0.05 \%$ Triton X-100 in universal bottles containing glass beads. Conidial suspensions were vortexed for $5 \mathrm{~min}$ to produce a homogenous suspension. Spore concentrations were determined using a haemocytometer. The viability of conidia was determined before any bioas-

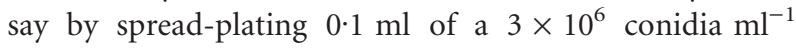

suspension onto 9-cm Petri dishes containing SDA medium. A sterile microscope cover slip was placed on each plate, and the plates were incubated in complete darkness at $25 \pm 2^{\circ} \mathrm{C}$ and examined after $20 \mathrm{~h}$. Percentage of germination of conidia was determined by assessing the number of germ tubes formed among 100 random conidia on the surface area covered by each cover slip under the light microscope $(400 \times)$. Four replicate plates of the isolates were used.

\section{Screening of fungal isolates}

Ten millilitres of standard concentration of $1 \times 10^{7}$ conidia $\mathrm{ml}^{-1}$ was sprayed on pods of French beans using a Burgerjon spray tower (Burgejon 1956). Pods were allowed to dry for $5 \mathrm{~min}$, after which they were transferred to $30-\mathrm{ml}$ glass tubes. Twenty 2 nd-instard larvae of WFT were then introduced gently in glass tubes using camel brush. In the control treatments, pods were sprayed with sterile distilled water containing $0.05 \%$ Triton $\mathrm{X}-100$. Treatments were randomized, and the experiment was replicated four times over time.

Dose-mortality relationships were calculated for the most pathogenic isolates using five doses of inoculum: $3 \times 10^{6} ; 1 \times 10^{7} ; 3 \times 10^{7} ; 1 \times 10^{8}$ and $3 \times 10^{8}$ conidia $\mathrm{ml}^{-1}$. Test insects were incubated at $25 \pm 2{ }^{\circ} \mathrm{C}$ and $90 \pm 2 \%$ r.h. with a photoperiod of $12 \mathrm{~L}: 12 \mathrm{D}$. Mortality was recorded daily for 10 days. Dead insects were placed in a humid chamber to allow the development of

Table 1 List of fungal isolates and their origin tested against second-instar larvae of Frankliniella occidentalis and percentage of germination after $16 \mathrm{~h}$ on SDA plates at $25 \pm 1^{\circ} \mathrm{C}$

\begin{tabular}{|c|c|c|c|c|}
\hline Fungal species & Isolates & Locality (country) & Source & $\begin{array}{l}\text { Percentage of } \\
\text { germination }\end{array}$ \\
\hline \multirow[t]{10}{*}{ Metarhizium anisopliae } & ICIPE 7 & Rusinga Island (Kenya) & Amblyoma variegatum & $92 \cdot 0 \pm 1 \cdot 6$ \\
\hline & ICIPE 18 & Mbita (Kenya) & Soil & $92 \cdot 8 \pm 1 \cdot 6$ \\
\hline & ICIPE 20 & Migori-Kenya & Soil & $96 \cdot 5 \pm 0.8$ \\
\hline & ICIPE 30 & Kendu Bay (Kenya) & Busseola fusca & $89 \cdot 4 \pm 1 \cdot 2$ \\
\hline & ICIPE 41 & Migori (Kenya) & Soil & 100 \\
\hline & ICIPE 69 & Matete (DRC) & Soil & $93 \cdot 5 \pm 0.6$ \\
\hline & ICIPE 78 & Ungoye (Kenya) & Temnoschoita nigroplagiata & $90 \cdot 7 \pm 1 \cdot 0$ \\
\hline & ICIPE 84 & (Senegal) & Ornitacris turbida & 100 \\
\hline & ICIPE 625 & Kabuti (Kenya) & Soil & 100 \\
\hline & ICIPE 665 & Ahero Plains (Kenya) & Soil & $92 \cdot 8 \pm 1 \cdot 3$ \\
\hline \multirow[t]{8}{*}{ Beauveria bassiana } & ICIPE 279 & Kericho (Kenya) & Coleopteran larvae & $97 \cdot 0 \pm 0 \cdot 7$ \\
\hline & ICIPE 284 & Mauritius & Soil & $95 \cdot 0 \pm 0 \cdot 7$ \\
\hline & ICIPE 620 & Kapsorok (Kenya) & Soil & 100 \\
\hline & ICIPE 621 & Motinet (Kenya) & Soil & 100 \\
\hline & ICIPE 622 & Kapiti sondu (Kenya) & Soil & 100 \\
\hline & ICIPE 646 & (Mauritius) & Soil & $96 \cdot 8 \pm 0.9$ \\
\hline & ICIPE 659 & Kapmonyok (Kenya) & Soil & 100 \\
\hline & ICIPE 664 & Bungoma (Kenya) & Soil & 100 \\
\hline
\end{tabular}


mycosis on the surface of cadaver. Each treatment consisted of four replicates of 20 insects each and was repeated three times.

\section{Conidial production}

Fungal isolates with the lowest median lethal concentration $\left(\mathrm{LC}_{50}\right)$ values were compared for conidial production. Second-instar larvae of WFT were exposed for $24 \mathrm{~h}$ to fungus-treated French bean pods at the concentration of $1 \times 10^{8}$ conidia $\mathrm{ml}^{-1}$, after which they were transferred onto sterile glass tubes containing clean pods. At 3, 6 and 9 days postinfection, five mycosed insects were collected and dried in an oven for $30 \mathrm{~min}$ at $30 \pm 1^{\circ} \mathrm{C}$ and transferred individually into $2-\mathrm{ml}$ cryogenic tubes containing $0.1 \mathrm{ml}$ of sterile $0 \cdot 05 \%$ Triton X-100. The tube was then vortexed for $5 \mathrm{~min}$ to dislodge conidia from the insect, and the number of conidia was determined using a haemocytometer (Hausser Scientific, Horsham, Pennsylvania, USA). The experiment was repeated four times.

\section{Characterization of fungal isolates based on internally transcribed spacer (ITS) sequences}

DNA extraction. Pure cultures of $M$. anisopliae isolates ICIPE 7, ICIPE 20 and ICIPE 69 were produced on SDA. Equal amounts $(0 \cdot 1 \mathrm{~g})$ of conidia of each of the isolates were weighed in microcentrifuge tubes on a weighing balance (Mettler AT 261 Delta, Listers 2000, USA). DNA was extracted using a slight modification of the CTAB method described by Doyle and Doyle and resuspended in prewarmed sterile deionized water. The primer pairs n-SSU1766-5 (ITS5) and nu-LSU-0041-3 (ITS4) (White et al. 1990) were used to amplify the ITS of the genomic DNA. PCR amplification reactions were carried out in a total volume of $20 \mu \mathrm{l}$ containing PCR buffer (Genscript, Piscataway, NJ, USA), $2.5 \mathrm{mmol} \mathrm{l}^{-1}$ of each dNTP (Genscript), $0 \cdot 2 \mu \mathrm{l}$ of each primer, $2.5 \mathrm{mmol} \mathrm{l}^{-1}$ of $\mathrm{MgCl}_{2}, 0.5$ units Taq DNA polymerase (Genscript) and c. $25 \mathrm{ng}$ of genomic DNA. PCR amplification conditions involved initial denaturation at $94^{\circ} \mathrm{C}$ for $3 \mathrm{~min}$, followed by 30 cycles of $94^{\circ} \mathrm{C}$ for $40 \mathrm{~s}$, annealing temperature of $52^{\circ} \mathrm{C}$ for $40 \mathrm{~s}$ with an extension at $72^{\circ} \mathrm{C}$ for $1 \mathrm{~min}$ and final elongation at $72^{\circ} \mathrm{C}$ for $10 \mathrm{~min}$. These reactions were carried out on a PTC100 thermocycler (MJR Inc., Minneapolis, MN, USA). Negative controls without fungal DNA were run for each experiment to check for contamination of reagents.

DNA quantification and sequencing. The amplification products were separated by electrophoresis in $1 \%$ agarose gels containing ethidium bromide $(3 \mu \mathrm{l})$, in $1 \times$ TAE buffer for $1 \mathrm{~h}$ at $70 \mathrm{~V} \mathrm{~cm}^{-1}$. DNA was visualized under UV light and recorded using a Kodak Gel imaging system
(Gel logic 200; Carestream Health, New Haven, CT, USA). The lengths of the amplicon products were estimated by comparison with 1-kb Smart DNA ladder (Noxo, Tallinn, Estonia). The PCR products were purified using QuickClean DNA gel extraction kit (Genscript) and sequencing outsourced.

\section{Data analysis}

Per cent mortality was corrected for control mortality (Abbott 1925) and normalized by arcsine transformation. Data were analysed using analysis of variance (ANOvA) using PROC GLM (sas ver. 9.2.; SAS lnc., Cary, NC) at 95\% level of significance. Means were separated using Student-Newman-Keuls (SNK). Median lethal time $\left(\mathrm{LT}_{50}\right)$ and $\mathrm{LC}_{50}$ were estimated using logistic regression. A Pearson correlation analysis was carried out to relate mortality rate with the conidial production.

DNA sequences of the most virulent fungal isolates were edited using Bioedit (ver. 7.0.5.3) (Hall 1999) and aligned using Clustal W (ver. 2.012) (Larkin et al. 2001) software.

A Basic Local Alignment Search Tool (BLAST) was performed using NCBI, EMBL and Fungal Genome Search databases. The first best hit accession number was considered.

\section{Results}

Conidial viability of the isolates varied between 89 and $100 \%$ (Table. 1). Mortality in the controls was low and did not exceed $15 \%$ in all the experiments. All tested fungal isolates were pathogenic to the second-instar WFT at the concentration of $1 \times 10^{7}$ conidia $\mathrm{ml}^{-1}$, causing mortalities of between 24 and 56\% (Table 2). Metarhizium anisopliae isolates ICIPE 20 and ICIPE 69 caused the highest mortality and were significantly different from only two other isolates (ICIPE 30 and 78) and six of the B. bassiana isolates $\left(\right.$ ICIPE 646, 659, 284, 279, 664 and 622) $\left(F_{17,195}=17 \cdot 37\right.$, $P<0.001)$. B. bassiana isolates ICIPE 664 and ICIPE 622 caused the lowest mortalities. Metarhizium anisopliae isolates ICIPE 7, ICIPE 20, ICIPE 69 and ICIPE 665 had the shortest $\mathrm{LT}_{50}$ values causing mortalities within $8 \cdot 0-8 \cdot 9$ days as compared to the other fungal isolates (Table 2).

Among the seven isolates of M. anisopliae and one isolate of $B$. bassiana selected for lethal concentration response bioassays, $M$. anisopliae isolate ICIPE 69 had the lowest $\mathrm{LC}_{50}$ value followed by ICIPE 7 and ICIPE 20 (Table 3). However, there were significant differences between ICIPE 69 and ICIPE 20. There were also no significant differences between ICIPE 69 and ICIPE 7 and between ICIPE 7 and ICIPE 20 (95\% confidence interval using fiducial limit overlapping). Metarhizium anisopliae isolate ICIPE 69 produced significantly more conidia than 


\begin{tabular}{|c|c|c|c|c|}
\hline Fungal species & Isolates & Mortality $(\% \pm \mathrm{SE})$ & $\mathrm{LT}_{50}$ (days) $(95 \% \mathrm{Cl})$ & Slope $( \pm$ SE) \\
\hline \multirow{10}{*}{$\begin{array}{l}\text { Metarhizium } \\
\text { anisopliae }\end{array}$} & ICIPE 20 & $56 \cdot 2 \pm 2 \cdot 9 a$ & $8.5(8 \cdot 3-8.8)$ & $4 \cdot 7 \pm 0 \cdot 1$ \\
\hline & ICIPE 69 & $55 \cdot 9 \pm 1 \cdot 9 a$ & $8 \cdot 2(8.0-8.4)$ & $4 \cdot 1 \pm 0 \cdot 1$ \\
\hline & ICIPE 7 & $51 \cdot 2 \pm 5 \cdot 0 a b$ & $8 \cdot 3(8 \cdot 0-8 \cdot 5)$ & $4 \cdot 0 \pm 0 \cdot 1$ \\
\hline & ICIPE 665 & $49 \cdot 6 \pm 3 \cdot 0 a b$ & $8 \cdot 4(8 \cdot 1-8 \cdot 7)$ & $3 \cdot 7 \pm 0 \cdot 1$ \\
\hline & ICIPE 18 & $44 \cdot 1 \pm 3 \cdot 0 a b c$ & $10 \cdot 6(10 \cdot 1-11 \cdot 2)$ & $2 \cdot 8 \pm 0 \cdot 1$ \\
\hline & ICIPE 41 & $48 \cdot 2 \pm 3 \cdot 5 a b c$ & $9 \cdot 2(9 \cdot 0-9 \cdot 6)$ & $4 \cdot 0 \pm 0 \cdot 1$ \\
\hline & ICIPE 625 & $48 \cdot 3 \pm 3 \cdot 5 a b c$ & $10 \cdot 5(10 \cdot 1-10 \cdot 6)$ & $4 \cdot 3 \pm 0 \cdot 1$ \\
\hline & ICIPE 84 & $43 \cdot 3 \pm 2 \cdot 5 a b c$ & $11 \cdot 3(10 \cdot 8-11 \cdot 9)$ & $3 \cdot 5 \pm 0 \cdot 1$ \\
\hline & ICIPE 30 & $40 \cdot 4 \pm 4 \cdot 0 \mathrm{bcd}$ & $11 \cdot 8(11 \cdot 2-12 \cdot 4)$ & $3 \cdot 7 \pm 0 \cdot 1$ \\
\hline & ICIPE 78 & $40 \cdot 9 \pm 3 \cdot 2 \mathrm{bcd}$ & $11 \cdot 1(10 \cdot 7-11 \cdot 7)$ & $3 \cdot 6 \pm 0 \cdot 1$ \\
\hline \multirow[t]{8}{*}{ Beauveria bassiana } & ICIPE 620 & $45 \cdot 9 \pm 2 \cdot 1 \mathrm{abc}$ & $10 \cdot 2(10 \cdot 0-10 \cdot 6)$ & $4 \cdot 7 \pm 0 \cdot 1$ \\
\hline & ICIPE 621 & $44 \cdot 6 \pm 2 \cdot 5 a b c$ & $11 \cdot 6(11 \cdot 1-12 \cdot 2)$ & $4 \cdot 1 \pm 0 \cdot 1$ \\
\hline & ICIPE 646 & $42 \cdot 5 \pm 2 \cdot 5 b c$ & $10 \cdot 5(10 \cdot 0-11 \cdot 0)$ & $3 \cdot 4 \pm 0 \cdot 1$ \\
\hline & ICIPE 659 & $38 \cdot 0 \pm 2 \cdot 3 \mathrm{bcd}$ & $12 \cdot 9(12 \cdot 2-13 \cdot 7)$ & $3 \cdot 9 \pm 0 \cdot 1$ \\
\hline & ICIPE 284 & $35 \cdot 0 \pm 4 \cdot 2 \mathrm{~cd}$ & $14 \cdot 8(13 \cdot 9-16 \cdot 0)$ & $3 \cdot 5 \pm 0 \cdot 1$ \\
\hline & ICIPE 279 & $29 \cdot 9 \pm 2 \cdot 8$ de & $17 \cdot 7(16 \cdot 2-19 \cdot 6)$ & $2 \cdot 6 \pm 0 \cdot 1$ \\
\hline & ICIPE 664 & $24 \cdot 6 \pm 2 \cdot 0 e$ & $24 \cdot 8(21 \cdot 9-28 \cdot 7)$ & $2 \cdot 7 \pm 0 \cdot 1$ \\
\hline & ICIPE 622 & $23 \cdot 8 \pm 1 \cdot 4 \mathrm{e}$ & $33 \cdot 0(27 \cdot 8-40 \cdot 7)$ & $2 \cdot 0 \pm 0 \cdot 1$ \\
\hline
\end{tabular}

Within column means followed by the same letters are not significantly different by StudentNewman-Keuls $(P<0.05)$.

\begin{tabular}{|c|c|c|c|}
\hline Species & Isolates & $\begin{array}{l}\mathrm{LC}_{50}(95 \% \mathrm{Cl}) \\
\left(\times 10^{8} \text { conidia } \mathrm{ml}^{-1}\right)\end{array}$ & Slope $( \pm$ SE) \\
\hline \multirow[t]{7}{*}{ Metarhizium anisopliae } & ICIPE 69 & $0 \cdot 1(0 \cdot 0-0 \cdot 1)$ & $2 \cdot 1 \pm 0 \cdot 1$ \\
\hline & ICIPE 7 & $0.2(0.1-0.2)$ & $1 \cdot 2 \pm 0 \cdot 0$ \\
\hline & ICIPE 20 & $0.3(0.2-0.3)$ & $1 \cdot 1 \pm 0 \cdot 0$ \\
\hline & ICIPE 41 & $0.8(0.6-1.0)$ & $0.9 \pm 0.0$ \\
\hline & ICIPE 84 & $3.6(2.5-5.8)$ & $1 \cdot 0 \pm 0.0$ \\
\hline & ICIPE 18 & $18(8 \cdot 1-58 \cdot 0)$ & $0.7 \pm 0.0$ \\
\hline & ICIPE 625 & $4 \cdot 0(2 \cdot 8-6 \cdot 4)$ & $1 \cdot 0 \pm 0.8$ \\
\hline Beauveria bassiana & ICIPE 620 & $14 \cdot 4(7 \cdot 5-36 \cdot 6)$ & $0 \cdot 8 \pm 0.1$ \\
\hline
\end{tabular}

Table 2 Virulence of fungal isolates against second-instar larvae Frankliniella occidentalis: Per cent mortality and $\mathrm{LT}_{50}$ values at the concentration of $10^{7}$ conidia $\mathrm{ml}^{-1} 10$ days posttreatment
Table 3 Lethal concentration values $\left(\mathrm{LC}_{50}\right)$ of selected fungal isolates against second-instar larvae of Frankliniella occidentalis the other two isolates in all the three sampling dates $\left(F_{2,31}=8.9, P<0.0009\right)$ (Fig. 1$)$. The conidia production was significantly different between the sampling days 3, 6 and 9 days $\left(F_{2,31}=18 \cdot 9, P<0 \cdot 0001, \mathrm{SNK}\right)$ postinfection

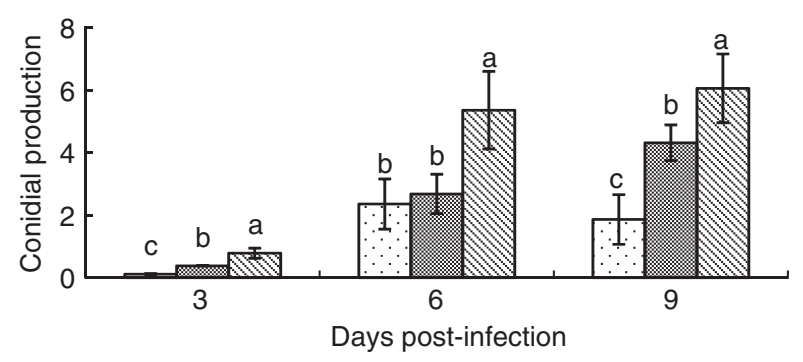

Figure 1 Mean conidial production $\left(\times 10^{5}\right.$ conidia) of three isolates of Metarhizium anisopliae following infection of second-instar larvae of

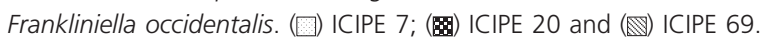

(Fig. 2). A correlation between conidial production and mortality (Pearson $R=0.65, P<0.001$ ) was observed (Table 4).

ITS sequences alignment showed a difference of two base pairs on the isolate ICIPE 69, which is not present in ICIPE 7 and ICIPE 20. The latter two were identical at this locus on the other isolates. Restriction sites were identified on the ITS sequence EcoR 1 and ZhoI and were common for all the three M. anisopliae isolates. However, $S f o I$ restriction site was found to be specific to M. anisopliae ICIPE 69 (Fig. 2).

A Basic Local Alignment Search Tool on NCBI, EMBL and Fungal Genome Search indicated a low expect $\operatorname{value}(E)$ and similarity values ranging between 97 and 100\% with Metarhizium anisopliae FJ545302, FJ609312 respectively on NCBI and EMBL. The Fungal Genome Search database identified the isolates as affiliated to M. anisopliae variety anisopliae AF136376 (Table 5). 


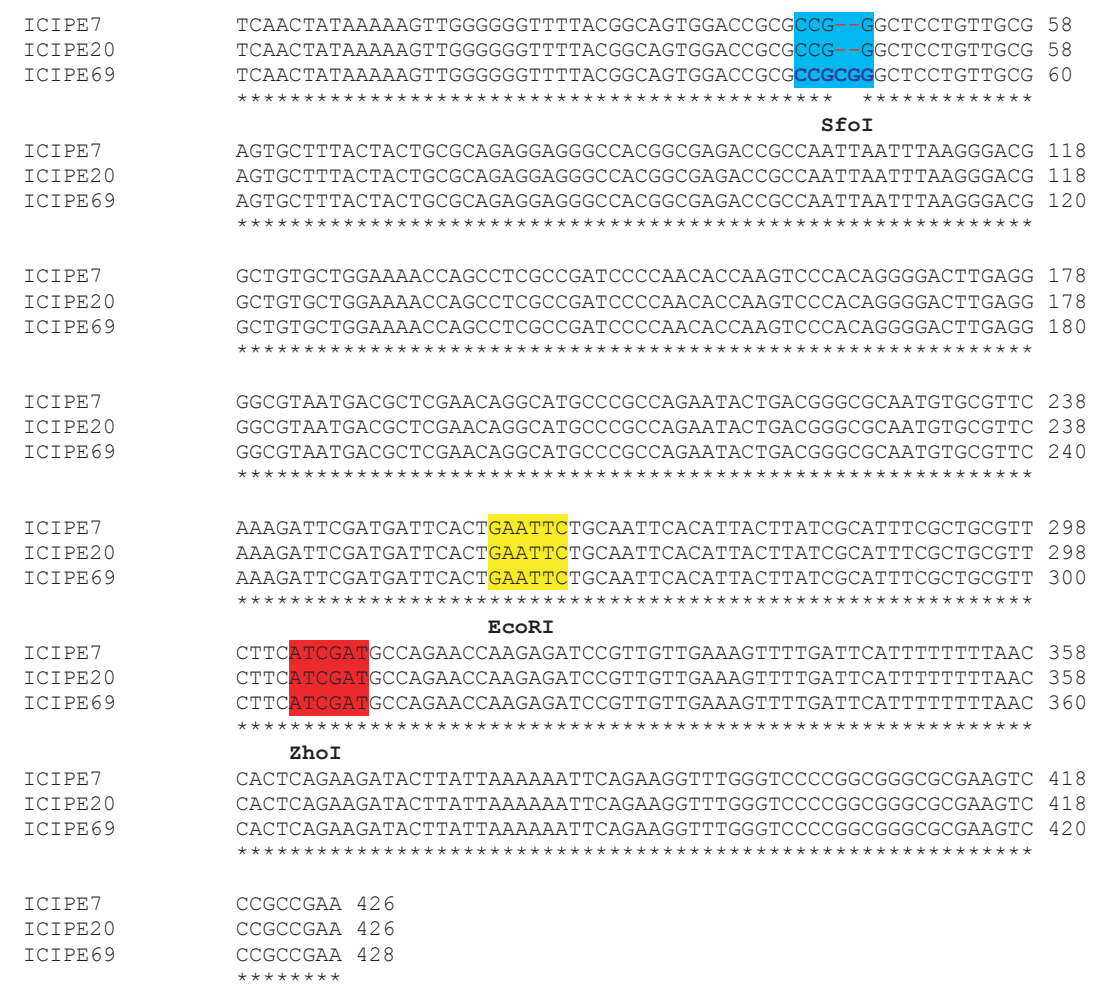

Figure 2 ITS4-ITS5 sequence alignments of DNA of three Metarhizium anisopliae isolates ICIPE 7, ICIPE 20 and ICIPE 69 showing the restriction sites EcoR1, Zhol and Sfol. Sections of the two sequences marked and unmarked with asterisks indicate homology and divergence, respectively, between the sequences.

Table 4 Correlation between mortality and conidial production of three Metarhizium anisopliae isolates ICIPE 7, ICIPE 20 and ICIPE 69 applied on second-instar larvae of Frankliniella occidentalis at $1 \times 10^{8}$ conidia $\mathrm{ml}^{-1}$

\begin{tabular}{lll}
\hline Isolates & $\begin{array}{l}\text { Mean } \\
\text { mortality }(\%)\end{array}$ & $\begin{array}{l}\text { Mean conidial } \\
\text { production } \\
\left(\times 10^{5} \text { conidia }\right)\end{array}$ \\
\hline ICIPE 7 & $55 \cdot 5 \pm 6 \cdot 7$ & $2 \cdot 5 \pm 0 \cdot 9$ \\
ICIPE 20 & $50 \cdot 8 \pm 7 \cdot 6$ & $3 \cdot 4 \pm 1 \cdot 2$ \\
ICIPE 69 & $70 \cdot 9 \pm 10 \cdot 5$ & $6 \cdot 9 \pm 2$ \\
\hline
\end{tabular}

Pearson: $R=0.65 ; P<0.0001 ; N=36$.

\section{Discussion}

The aim of this study was to identify potential fungal candidate(s) for control of the larval stage of F. occidentalis that has been reported to be refractory to fungal infection (Vestergaard et al. 1995; Maniania et al. 2002; Ugine et al. 2005). All the fungal isolates tested were pathogenic to the second-instar larvae of WFT; however, mortality and $\mathrm{LT}_{50}$ values varied between the isolates. Such variations have already been reported for fungal pathogens in many groups of insects (Ekesi et al. 1998; Mburu et al. 2009;
Migiro et al. 2010). Four isolates of M. anisopliae (ICIPE 20, ICIPE 69, ICIPE 7 and ICIPE 665) with $\mathrm{LT}_{50}$ between 8.0 and 8.8 days outperformed the other fungal isolates (Table 2). When seven isolates of M. anisopliae and one of $B$. bassiana were evaluated for the $\mathrm{LC}_{50}$ bioassays, only three isolates of M. anisopliae (ICIPE 7, ICIPE 20 and ICIPE 69) had the lowest $\operatorname{LC}_{50}\left(1-3 \times 10^{7}\right.$ conidia $\left.\mathrm{ml}^{-1}\right)$ (Table 3). Virulence has always been one of the most important parameters considered for strain selection (Inglis et al. 2001), whereas parameters such as persistence, UV tolerance and conidial production have been overlooked. In this study, the three best fungal isolates (lower $\mathrm{LC}_{50}$ values) were compared for conidial production. The M. anisopliae isolate ICIPE 69 produced significantly more conidia than the other isolates, which may be an advantage in terms of inoculum dispersion in the habitat, mass production and subsequent commercialization. The virulence of isolate ICIPE 69 against adults of the legume flower thrips, Megalurothrips sjostedti Trybom (Ekesi et al. 1998), onion thrips, Thrips tabaci Lindeman (Maniania et al. 2003) and WFT (Maniania et al. 2002), coupled with high conidial production and tolerance to broad range temperature (Ekesi et al. 1999), makes it a suitable biopesticide candidate for thrips control. More- 
Table 5 Basic Local Alignment Search Tool of Metarhizium anisopliae ICIPE 7, ICIPE 20 and ICIPE69 ITS4, ITS5 sequences using NCBI, EMBL and Fungal Genome Search databases

\begin{tabular}{|c|c|c|c|c|c|}
\hline Isolates & Length (bp) & $\begin{array}{l}\text { hit Accession } \\
\text { number }\end{array}$ & $\begin{array}{l}\text { Expect } \\
\text { value }(E)\end{array}$ & Identity (\%) & Species \\
\hline \multicolumn{6}{|l|}{ NCBI } \\
\hline ICIPE 7 & 426 & FJ545302 & $0 \cdot 0$ & 100 & M. anisopliae \\
\hline ICIPE 20 & 426 & FJ545302 & $0 \cdot 0$ & 100 & M. anisopliae \\
\hline ICIPE 69 & 428 & FJ545302 & $0 \cdot 0$ & 99 & M. anisopliae \\
\hline \multicolumn{6}{|l|}{ EMBL } \\
\hline ICIPE 7 & 426 & FJ609312 & $4 \cdot 3 e^{-85}$ & 98 & M. anisopliae \\
\hline ICIPE 20 & 426 & FJ609312 & $5 \cdot 3 e^{-86}$ & 98 & M. anisopliae \\
\hline ICIPE 69 & 428 & FJ609312 & $5 \cdot 3 e^{-86}$ & 97 & M. anisopliae \\
\hline \multicolumn{6}{|c|}{ Fungal Genome Search } \\
\hline ICIPE 7 & 426 & AF136376 & $6 \cdot 6 e^{-87}$ & & M. anisopliae var. anisopliae \\
\hline ICIPE 20 & 426 & AF136376 & $6.6 e^{-87}$ & & M. anisopliae var. anisopliae \\
\hline ICIPE 69 & 428 & AF136376 & $5 \cdot 3 e^{-86}$ & & M. anisopliae var. anisopliae \\
\hline
\end{tabular}

over, Ekesi and Maniania (2000b) have established that ICIPE 69 can significantly alter feeding, fecundity, fertility and longevity of M. sjostedti. Because larval stages of thrips are known to be acquisition agents and replication hosts of viral proteins (Whitfield et al. 2005), hence ICIPE 69 can play an important role in the control of tospovirus epizooties.

The results of the ITS gene sequence amplification showed two base pair differences in ICIPE 69, which alter the restriction site sequence for SfoI. This restriction enzyme ( $S f o I)$ can be used to identify ICIPE 69 by the RFLP technique (Fig. 2).

A Basic Local Alignment Search Tool (вLAst) in NCBI, EMBL and Fungal Genome Search showed homology over $95 \%$ with $M$. anisopliae. However, the nucleotide sequences of the three isolates suggest intra-specific genotypic variation (Freed et al. 2011; Mburu et al. 2011). Geographical and ecological features of the fungal isolates may explain the variation observed in this study (Meyling and Eilenberg 2007; Bischoff et al. 2009; Enkerli and Widmer 2010). For instance, M. anisopliae isolate ICIPE 69 originated from the Democratic Republic of Congo, whereas the other two originated from Kenya. In conclusion, our results reconfirm the efficacy of the M. anisopliae isolate ICIPE 69 and suggest its development as fungal biopesticide for thrips management.

\section{Acknowledgements}

We are grateful to Dr S. Dara, University of California, Davis, for reviewing the first draft of the manuscript, and Miss Barbara Obonyo for technical support. We also thank Joel Ltilitan Bargul for assistance with the molecular work. This study was jointly funded by the German Academic Exchange Services through the African Regional
Postgraduate Programme in Insect Science (ARPPIS; http://www.icipe.org/arppis) of icipe and the Federal Ministry for Economic Cooperation and Development, Germany (BMZ) through the Thrips IPM Project.

\section{References}

Abbott, W.S. (1925) A method of computing the effectiveness of an insecticide. J Econ Entomol 18, 265-267.

Bischoff, J.F., Rehner, S.A. and Humber, R.A. (2009) A multilocus phylogeny of the Metarhizium anisopliae lineage. Mycologia 101, 512-530.

Broughton, S. and Herron, G.A. (2009) Potential new insecticides for the control of western flower thrips (Thysanoptera: Thripidae) on sweet pepper, tomato, and lettuce. $J$ Econ Entomol 102, 646-651.

Burgejon, A. (1956) Pulverisation de poudrage au laboratoire par des preparations pathogens insecticides. Ann Epiphyties 4, 677-688.

Ekesi, S. and Maniania, N.K. (2000a) Metarhizium anisopliae: an effective biological control agent for the management of thrips in horti and floriculture in Africa. In Advances in Microbial Control of Insects Pests ed. Upadhyay, R.K. pp. 165-191. New York: Kluwer Academic/Plenum publishers.

Ekesi, S. and Maniania, N.K. (2000b) Susceptibility of Megalurothrips sjostedti developmental stages to Metarhizium anisopliae and the effects of infection on feeding, adult fecundity, egg fertility and longevity. Entomol Exp Appl 94, 229-236.

Ekesi, S., Maniania, N.K., Onu, I. and Lohr, B. (1998) Pathogenicity of entomopathogenic fungi (Hyphomycetes) to the legumes flower thrips, Megalurothrips sjostedti (Thysanoptera: Thripidae). J Appl Entomol 122, 629-634.

Ekesi, S., Maniania, N.K. and Ampong-Nyarko, K. (1999) Effect of temperature on germination, radial growth and virulence of Metarhizium anisopliae and Beauveria bassiana 
on Megalurothrips sjostedti. Biocontrol Sci Technol 9, 177-185.

Ekesi, S., Dimbi, S. and Maniania, N.K. (2007) The Role of entomopathogenic fungi in the integrated management of fruit flies (Diptera: Tephritidae) with emphasis on species occurring in Africa. In Use of Entomopathogenic Fungi in Biological Pest Management ed. Ekesi, S. and Maniania, N.K. pp. 239-274. Trivandrum, Kerala, India: Research Signpost Publishers.

Enkerli, J. and Widmer, F. (2010) Molecular ecology of fungal entomopathogens: molecular genetic tools and their applications in population and fate studies. Biocontrol 55, $17-37$.

EPPO (2002) Diagnostic protocols for regulated pests Frankliniella occidentalis. EPPO Bull 2, 281-292.

Freed, S., Jin, F.-L. and Ren, S.-X. (2011) Determination of genetic variability among the isolates of Metarhizium anisopliae var. anisopliae from different geographical origins. World J Microbiol Biotechnol 27, 359-370.

Hall, T.A. (1999) BioEdit: a user-friendly biological sequence alignment editor and analysis program for Windows 95/98/NT. Nucleic Acids Symp Ser 41, 95-98.

Inglis, D.G., Goettel, S.M., Butt, M.T. and Strasser, H. (2001) Use of hyphomycetes fungi for managing insect pests. In Fungi as Biocontrol Agents ed. Butt, T.M., Jackson, C. and Magan, N. pp. 23-27. Wallingford: CABI Publishing.

Jensen, E.S. (2004) Insecticide resistance in the Western flower thrips, Frankliniella occidentalis. Integr Pest Manag Rev 5, 131-146.

Kirk, W.D.J. and Terry, L.I. (2003) The spread of the Western flower thrips Frankliniella occidentalis (Pergande). Agric Forest Entomol 5, 301-310.

Larkin, M.A., Blackshields, G., Brown, N.P., Chenna, R., McGettigan, P.A., McWilliam, H., Valentin, F., Wallace, I.M. et al. (2001) Clustal W and Clustal X version 2.0. Bioinformatics 23, 2947-2948.

Lewis, T. (1997) Thrips as Crop Pests. Oxon, UK: CAB Wallingford.

Maniania, N.K., Ekesi, S., Lohr, B. and Mwangi, F. (2002) Prospect for biological control of the Western Flower Thrips, Frankliniella occidentalis, with the entomopathogenic fungus, Metarhizium anisopliae on Chrysanthemum. Mycopathologica 155, 229-235.

Maniania, N.K., Sithanantham, S., Ekesi, S., Onu, I., AmpongNyarko, K., Baumgärtner, J., Löhr, B. and Matoka, C.M.
(2003) A field trial of the entomopathogenous fungus Metarhizium anisopliae for control of onion thrips, Thrips tabaci. Crop Prot 22, 553-559.

Mburu, D.M., Ochola, L., Maniania, N.K., Njagi, P.G.N., Gitonga, L.M., Ndung'u, M.W., Wanjoya, A.K. and Hassanali, A. (2009) Relationship between virulence and repellency of entomopathogenic isolates of Metarhizium anisopliae and Beauveria bassiana to the termite Macrotermes michaelseni. J Insect Physiol 55, 774-780.

Mburu, D.M., Ndung'u, M.W., Maniania, N.K. and Hassanali, A. (2011) Comparison of volatile blends and gene sequences of two isolates of Metarhizium anisopliae of different virulence and repellency toward the termite Macrotermes michaelseni. J Exp Biol 214, 956-962.

Meyling, N.V. and Eilenberg, J. (2007) Ecology of the entomopathogenic fungi Beauveria bassiana and Metarhizium anisopliae in temperate agroecosystems: potential for conservation biological control. Biol Control 43, 145-155.

Migiro, L.N., Maniania, N.K., Chabi-Olaye, A. and Vandenberg, J. (2010) Pathogenicity of entomopathogenic fungi Metarhizium anisopliae and Beauveria bassiana (Hypocreales: Clavicipitaceae) isolates to the adult pea leafminer (Diptera: Agromyzidae) and prospects of an autoinoculation device for infection in the field. Environ Entomol 39, 468-475.

Nderitu, J.H., Kasina, J.M. and Nyamasyo, G.N. (2008) Management of thrips (Thysanoptera: Thripidae) on French bean (Fabaceae) in Kenya: economics of insecticide applications. J Entomol 5, 148-155.

Ugine, T.A., Wraight, S.P. and Sanderson, J.P. (2005) Acquisition of lethal doses of Beauveria bassiana conidia by Western flower thrips, Frankliniella occidentalis, exposed to foliar spray residues of formulated and unformulated conidia. J Invertebr Pathol 90, 10-23.

Vestergaard, S., Gillespie, A. T., Butt, T. M., Schreiter, G. and Eilenberg, J. (1995) Pathogenicity of the Hyphomycete Fungi Verticillium lecanii and Metarhizium anisopliae to the Western Flower Thrips, Frankliniella occidentalis. Biocontrol Sci Technol 5, 185-192.

White, T.J., Bruns, T., Lee, S. and Taylor, J.W. (1990) Amplification and Direct Sequencing of Fungal Ribosomal RNA Genes for Phylogenetics. New York: Academic Press.

Whitfield, A.E., Ullman, D.E. and German, T.L. (2005) Tospovirus-Thrips interactions. Annu Rev Phytopathol 43, 9-89. 